\title{
Learning Model of Narative Writing in Elementary School Reviewed from The Perspective of Balance of Brain Function
}

\author{
Ririen Wardiani ${ }^{1}$, Suwandi $^{2}$, Andayani $^{3}$, Budiyono $^{4}$ \\ \{ririenw@student.uns.ac.id ${ }^{1}$, sarwijiswan@staff.uns.ac.id ${ }^{2}$, buanda09@yahoo.co.id ${ }^{3}$, \\ budiyono53@yahoo.com ${ }^{4}$ \}
}

Program Studi Pendidikan Bahasa Indonesia STKIP PGRI, Ukel 39, Ponorogo, Jawa Timur, Indonesia ${ }^{1}$, Post Graduate Universitas Sebelas Maret, Surakarta, Indonesia ${ }^{2,3,4}$

\begin{abstract}
Writing is a vital skill for students to have. This research uses descriptive research methods that aim to improve the learning of narrative writing. This research was conducted at SDN 1 Pondok Kabupaten Ponorogo, SD Muhammadiyah Terpadu, and SDN 1 Jenangan. Data collection techniques are through observation, interviews, document analysis, and composition tests. Implementation of learning narrative writing in perspective of balancing of the brain function begins with a gradual learning structure with balanced brain activity through tangible objects, media images, audiovisual, music, and others. Giving stimulation based on right and left hemisphere of the brain functions provides a pleasing learning effect to students. It was proven that results of writing narrative students have improved both in content aspects, organization of content, vocabulary, grammar and spelling.
\end{abstract}

Keywords: Learning model, narrative writing, balancing brain function.

\section{Introduction}

Writing is the most important skills students have. This is because writing is the initial provision of a student in determining the success of learning other subjects and as a basis for students to obtain higher education later. Writing becomes a means to extend students' understanding of the lessons and is the most important language skills. This is insisted by Percy [1] which states that writing is a tool for understanding. Writing has benefits as a means to develop an understanding of something and the ability to use language (a tool for developing and understanding of and ability to use the language).

Pennebaker also mentions some of the advantages of writing activities such as clearing the mind, overcoming trauma, helping to gain and remember new information, solving problems, and free-writing can be helpful when forced to write [2]. He explains that expressive writing can change attitudes and behaviour, increase creativity, memory, motivation, and various relationships between health and behaviour.

Based on the above explanation can be assumed that writing is an ability that is important for students to have. It is also useful to write emotional expressions into books, blogs or personal journals in narrative form. There are many benefits both physically and psychologically even in behaviour that can be obtained when students write. Writing helps students get and remember new information. 
A concise view of the stage of the writing course is expressed process is expressed by Tompkins a brief overview of the stages of the writing process is expressed by Tompkins presenting five stages: (1) pre writing, (2) drafting, (3) revising, (4) editing, and (5) publication / (sharing ). Tompkins also stresses that these writing stages are not linear activities. The writing process is nonlinear, meaning it is a recurring round. For example, after finishing editing the author, the author may wish to review its conformity with the original writing or draft frame [3]. There are three writing processes offered by Nunan (1990: 90) namely: (1) prewriting stage, (2) writing stage, and (3) improvement phase. To apply these three stages of writing requires skill to combine between process and product writing [4] generally includes: (1) prewriting stage, (2) writing stage, and (3) improvement stage. To apply these three stages of writing requires skill to integrate between the process and the product of writing.

Based on the stages of the process of writing the above teachers should be able to apply these stages in learning to write but most teacher do not apply this. Here I portray the results of research I do about how the condition of learning to write in schools. Based on the results of interviews and observations how students learn to narrative writing of 8 elementary schools in Ponorogo district, it was obtained results about the condition of teachers and students, learning process, and evaluation in learning to write narrative. The following will give details of the results of the study.

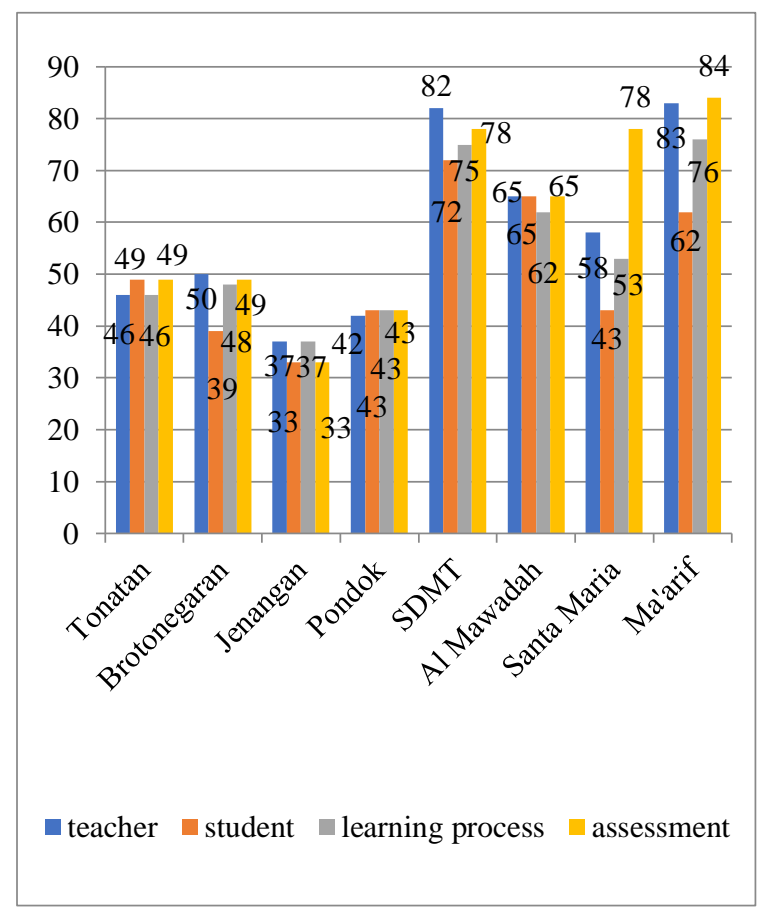

Fig. 1. Condition of Teacher, Student, Learning Process, and Assessment of Learning in Narrative Writing Lesson in Elementary School. 
Teacher learning quality can be examined from preliminary activities, core activities (exploration, elaboration, confirmation) and closing activities as well as teacher guidance in learning, providing examples, new techniques being tried and reflections of written results. Based on figure 1 above there are 4 schools that have met more than $50 \%$ good criteria. The four teachers have implemented a learning that meets the criteria, with the appealing that attracts students in the core activities to implement several variations of learning techniques, i.e.: using mind mapping, series of serial images and movies. Teachers also accompany students in learning to write and also show students' weakness of writing so that students know the mistakes that have been done.

Student quality is seen from student's interest/motivation, writing idea, spirit and creativity of students, mastery of knowledge of writing stages and enthusiasm of students in learning. Based on the figure above, there are 3 schools whose students have fulfilled more than $50 \%$ good criteria. In the three schools, the interest and motivation of students in learning writing has been seen. Students have quite creative writing idea. Some of the students in the school have enough knowledge of the writing stage. Students' Enthusiasm in learning is good enough.

The quality of the learning process can be examined from the learning stages from the introduction/apperception, core activities (exploration, elaboration, confirmation) and closing activities. It includes that the teacher has conducted a mentoring program in learning, providing examples, new techniques are tried and reflection of the writing. Based on figure 1 above there are 4 schools that have met more than $50 \%$ good criteria. The four schools that have implemented the learning process in line with the criteria, i.e.: they generally start learning with apperception that can attract students to follow the next lesson. The apperception is done by telling stories, guiding questions and relating to past material. In the average core activity of 4 schools above the criteria have done several variations of learning techniques.

The quality of evaluation in learning can be examined from the 3 points: accompaniment while carrying out the learning process, the reflection of writing and performing the assessment with a simple grid. Based on figure 1 above the school that has conducted an evaluation in the learning that has met the criteria of $50 \%$ are 4 schools. The four schools that have implemented the evaluation of learning in line with the criteria set generally do mentoring while implementing the learning process. Teachers also reflect on students' writing. But in doing the assessment still use a simple grid, such as just assessing the relationship title with the content and spelling only.

Departing from the facts of the above study, a model of learning in the perspective of balancing brain function is proposed. The view that the right and left brains have different functions inspires many educational theories. It is generally known that the left hemisphere organizes the right side of the body while the right brain organizes the left side of the body. Corpus Callosum serves a vital role as a bridge between the two brain hemispheres [5] reveal that the right hemisphere of his thinking process is random, irregular, intuitive, and holistic. The thinking process is in line with ways to know nonverbal, such as feelings and emotions, awareness of feelings (sensing the presence of an object or person, spatial awareness, recognition of shapes and patterns, music, art, color sensitivity, creativity, and visualization. While the left brain thinking process is logical, sequential, linear, and rational. The left brain based on reality is capable of performing abstract and symbolic interpretations. The thinking process is appropriate for regular tasks, verbal expressions, writing, reading, auditory associations, placing details and facts, phonetics, and symbolism.

Furthermore, [6] proposed a Whole Brain Learning for educational process, namely the concept of education that combines the task of the right brain and left brain. To balance the 
tendency toward the left brain, it is necessary to incorporate music and aesthetics in the learning experience and provide positive feedback. All of it poses a positive effect for you yourself. Positive emotions lead to the power of the brain that leads to success.

Brain-friendly learning according [7] should consider four main principles for applying in classroom learning. The four principles are Safety, Respect, Novelty, and Memory. Safety is a classroom should be safe, able to bring a sense of awareness and mutual trust before learning. Respect is that children will thrive when their unique amalgamation of learning styles is respected and supported. Novelty is a challenging, exciting, and new activity that raises a positive emotional state so that learning conditions can create pure bonds and learning opportunities. Memory is entering and building existing memory which affects pure learning and can keep new memory.

Based on the research of Roger Sperry [8] it reveals the difference in a constant way how both hemispheres store and process information. The results of these study support the existence of different functions between the two hemispheres. Many experts argue that the left brain is the IQ (Intelligence Quotient) controller, while the right brain serves a vital role for the development of EQ (Emotional Quotient). Both hemispheres have a very important role. Therefore, a person make a balance in every aspect of his life if he can optimize the ability of both hemispheres in a balanced way.

Humans are able to process the world in two ways. Rico [9] calls it the brain's sign and brain design. The brain of the sign (left hemisphere) thinks linearly, per section, logically, one by one, while the right brain thinks as a whole, illustrates by image, emotional net, sensory pattern, as the memory suddenly flashed in consciousness as a whole. Similarly in writing skills, Rico argues that although writing requires the work of the left brain, writing also requires a global search strategy for grouping, requiring nonlinear encouragement of emotions, memory, ideas from the right brain. The rushed emphasis on left-brain work often closes the right-brain search strategy. Once both sides of the brain have done accordingly in the writing process, the creative potential that already exists within us is all activated. The resulting writing flows quickly and easily.

There are several important roles of the brain in the process of creativity such as creativity, imagination, and intelligence. These components are very potential in the creative process. These three keywords are closely related to the function of the brain. The ability of creativity, the power of imagination is a function of the right brain. Intelligence is a function of the brain in general both the right and left brain functions.

Research related to writing learning in elementary school was conducted by Yu Shu Fan in Taiwan primary school. As performed in elementary school Taiwan, he found that the technique of thinking map in writing is very effective and facilitate students in learning writing. Other researchers analyzing writing skills in elementary schools were conducted by Fazio \& Gallagher. They discuss about writing creativity techniques [11]. Their research discusses about writing skills that can be developed with Mnemonic POWER (Planning, Organizing, Writing, Editing, Rewriting) techniques that are mostly emphasized on E (Editing). Other experts who did research writing skills in elementary school are Smitherman \& Girard. This study shows the success of students at the basic level because it integrates with other science. Smitherman \& Girard (2011) research offers a technique by creating a bridge of learning to write with creative writing. The bridge is called craft criticism. Craft criticism is a link between creative writing and learning materials [12].

Research on how the brain works associated with the writing and learning process in school looks like this. Shah et al., (2013) describes that the research of creative writing and copying is investigated by using media fMRI (functional Magnetic Resonance Imaging) a 
device that uses computer media that can see which part of the brain is active. The results show that creative writing involves the cognitive abilities, languages, and functions of the creative brain mainly represented in the parietal frontal temporal network. Based on the results of the images of the parietal frontal-temporal network of the brain when learner perform the creative writing activities, the right and left brain structures works simultaneously [13]. This is different from just writing activity in the form of copying activity. Review of various research results based on research conducted (Gülpinar, 2005, pp. 299-306) explains that research using electro psychological media, neuro psychological test affects the development of the world of education. It is also an impact of learning based on a constructivist approach. Learning based on constructivist view there are three important concepts namely individual differences, contextuality, and complexity [14]. Research conducted who examined the property of brain-based learning on student achievement with diverse learning styles. Duman's research was conducted on students of the Department of Social Science of Teacher Education at the Faculty of Education at Turkish Mugla University with a total of 68 respondents. The design used was a pre-test post-test design experiment. This study compared the academic skills performed with brain-based learning with traditional learning. The results confirm that brain-based learning is more effective. Brain-based learning is based on understanding individual differences through an understanding of learning styles. Understanding learning requires some knowledge of how the brain works and learns, and how brain function is based on the natural principle of brain work that adapts to the functioning of the brain [15].

Referring to previous research by Fazio \& Gallagher (2009), Smitherman \& Girard (2011), and Fan (2016), they appear to have more emphasis on writing techniques through Mnemonic POWER, writing that is associated with other disciplines, and techniques based on thingking map. In addition there are also studies that relate the performance of ota with the ability to write and learning in general [10],[11], [12]. Shah et al. shows with fMRI tools can be known when creative writing learning proved that the right hemisphere and left hemisphere work actively, while it does not work so when the activities of writing is only copying. Duman examines learning with individual learning styles. Understanding individual learning styles will be able to support success in learning when compared with traditional learning. Gulpinar provides some tenets of brain-based learning based on the effects of review of several studies utilizing neuroscience research results and the impact of constructivist approaches. The results of the review resulted in learning that respects individual differences, contextuality, and complexity.

Departing from that, it takes writing-learning techniques that are able to unravel the problem of writing skills that emphasize on how to get ideas, express ideas, develop imagination, and technically how to build the capacity to write by adhering to the system of good and right language. This can be realized by learning that optimizes the ability of both hemispheres in a balanced way. Balancing brain function makes it easy for students to express their ideas. Balancing brain function will produce complementary alloys. Feelings, emotions, imaginations which are the right-brain function of the expression are aided by the workings of the left brain. Writing is an entire brain activity that uses the right hemisphere (emotional) and the left hemisphere (logic) [5].

This research is focused on the implementation of learning narrative writing in perspective of balancing of the brain function. This narrative genre is chosen because writing narration is the most basic skill that children should master. This is in line with [16]. Martin explained that the ability to write narrative is the first step required to teach the writing process for students. 


\section{Method}

This research uses descriptive research method that aims to describe the use of learning model of narrative writing with the perspective of balancing brain function. This research was conducted in 3 schools: SD Muhammadiyah Terpadu with 24 students, SDN I Jenangan with 22 students, and SDN I Pondok with 26 students. The total number of respondents is 72 students. Technique of collecting data through observation, interview and performance test. Interviews were carried out with teachers and students, while observations were made on the lesson. The instruments that are used are interview guides and teacher and student observation guidelines. While the performances test is a test of narrative writing skills.

Data analysis using mastery learning technique adopted by Curriculum 2013 (K-13) and Education Unit Level Curriculum (KTSP). Mastery guide uses 100 scale assessment. Personal mastery guidance states that students are declared get completely mastery in learning if students get a score of 75. Classical mastery states students are declared to have complete mastery if $85 \%$ of students have completed a score of 75 . The success of research is based on the increase of the learning mastery.

\section{Result and Discussion}

The above problems are expected to be solved by introducing a fun and easy model to be perceived by students with different ways of learning and understanding. Teachers should know how students learn. This is in line point of view, et al. that the learning model chosen by the teacher is recommended in line with the student's learning style [17]. Joyce's exposure in introducing learning models is studied in a step-by-step activity tailored to student-based learning of brain functioning with whole brain or global learning. It also notes the phases of the writing process which consists of pre-writing, drafting, revision, editing, and publication. The following describes the syntax, social systems, principles of relations, support systems, in addition to the impact of instructional and companion impact of brain-based learning model of writing.

Based on these phases, below described how the stages of the implementation of writing based learning weighing brain function. Syntax in writing learning based on brain function weighing, the following learning steps.

Table 1. Steps of Writing Narrative Based on Balancing Brain Function.

\begin{tabular}{cllllll}
\hline ACTIVITY & BALANCING & THE & RIGHT & AND & LEFT & BRAIN \\
& FUNCTIONS & & & & & \\
\hline
\end{tabular}


Emotion Ignition

1) Teachers stimulate students 'emotions bringing a binding atmosphere to the students' experience using concrete objects, picture media, story texts and movies

2) The teacher arouses the students' imagination

\section{Clustering}

1) Teacher explains how to make clustering

2) The teacher gives examples of clustering

3) clustering is made using a series of events

\section{Expression}

1) Teacher explains how to express writing from clustering result.

2) The teacher gives examples of how to make essays from clustering and skeleton

3) Teachers motivate and provide reinforcement for students not to feel guilty in expressing their ideas.

Editing

1) The teacher takes a sample of student essays to be analyzed in a classical manner with regard to the contents of
Sparking emotions, the use of concrete objects, media images, movies, and music is the activity of the right brain. The activity is always accompanied by verbal exposure which is a left brain activity.

The working principle of clustering can be structured, hierarchy and relationships. The working principle is left brain activity. The activity is balanced by the use of colors, shapes, marks that are the activity of the right brain.

Expression is the expression of ideas, thoughts that are in memory through language. The use of this language is left cerebrum activity. Activities to balance is combined with imagination, intuition, creativity that is a right brain activity.

Edit activity is more dominant with left-brain activity. Because the functionality of the left-brain processes the inputs in a sequential (sequential) and analysis. This is balanced with right brain activity by signing, coloring and thinking in a holistic way. 
the proposed idea, content organization, the style (choice of structure and vocabulary) of grammar and spelling.

2) After discussing one example held a discussion with the students

3) Teachers provide assistance either classical or individual

4) The teacher expects students to improve the writing that will be ready for display.

\section{Display}

Shelf activity is a visual activity that is a right-brain activity balanced with verbal exposure.

Displaying student work in a classroom wall magazine or displayed in class according to their classroom condition.

\section{Reflection}

Evaluating is a left-brain activity activity. This is balanced by the design of the next activity which is the right brain activity

This activity begins once teacher analyzes students writing which have been edited.

Teachers and students make the next draft of activity

Based on the above table, shortly it can be showed in the following figure 2 . 


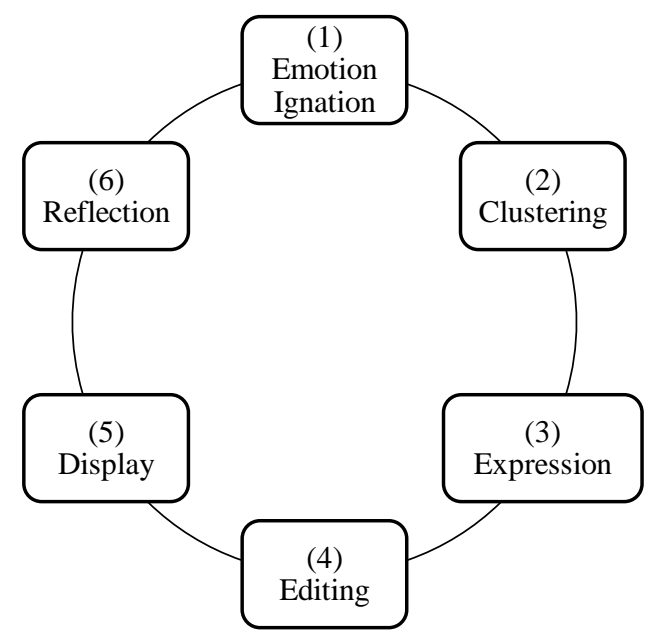

Fig. 2. Learning to Write Right-Based and Left Brain-Based Balancing Figures.

This study was conducted with two cycles. The first cycle of learning model based on balancing brain function is emphasized on giving emotional ignition with multi-sensory concrete objects. The function of giving emotional ignition is to bring students to the imagination of the object. The result of the first cycle shows students who achieve minimal criteria are 30 of 72 students or percentage of mastery achievement in the first cycle of $42 \%$. There is an progress in cycle 2 that shows the mastery achievement $85 \%$. It means that 61 of 72 students achieve minimal criteria.

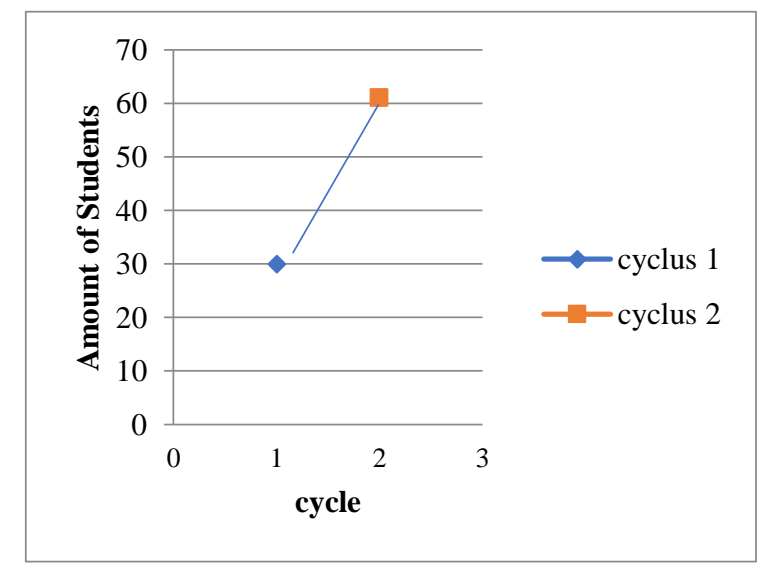

Fig. 3. Learning Result of Narrative Writing Using Clustering Technique Based on Balancing Brain Function.

Based on the assessed aspects, 4 of 72 students meet good criteria in content aspect, 64 students meet good criteria in organization content, 61 students in vocabulary, 23 students in grammar and 31 students in spelling. This is supported by the interviews that students feel that 
concrete objects and clustering that are linked to the storyline help them. It is demonstrated in Figure 4.

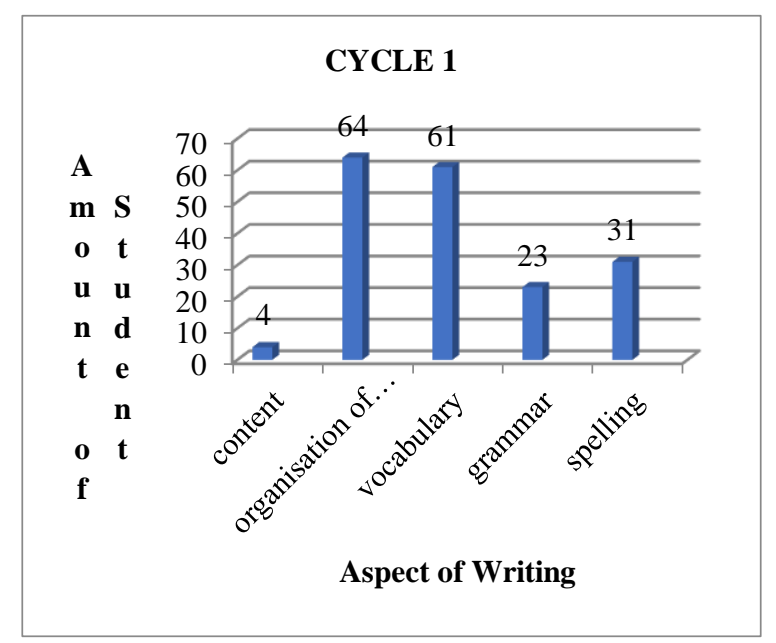

Fig. 4. Results of Narrative Writing Ability in Each Aspect of Cycle 1.

Implementation of the second cycle of learning using a learning model based on balancing brain function by lightening emotions with the film media and guided by a guide asked questions. The result of the second cycle obtained a complete student data of 61 students from 72 students. Percentage mastery in research in second cycle is $85 \%$. Based on the assessed aspects, 29 of 72 students meet good criteria in content aspect, 70 students meet good criteria in organization content, 71 students in vocabulary, 50 students in grammar and 52 students in spelling. It is demonstrated in Figure 5.

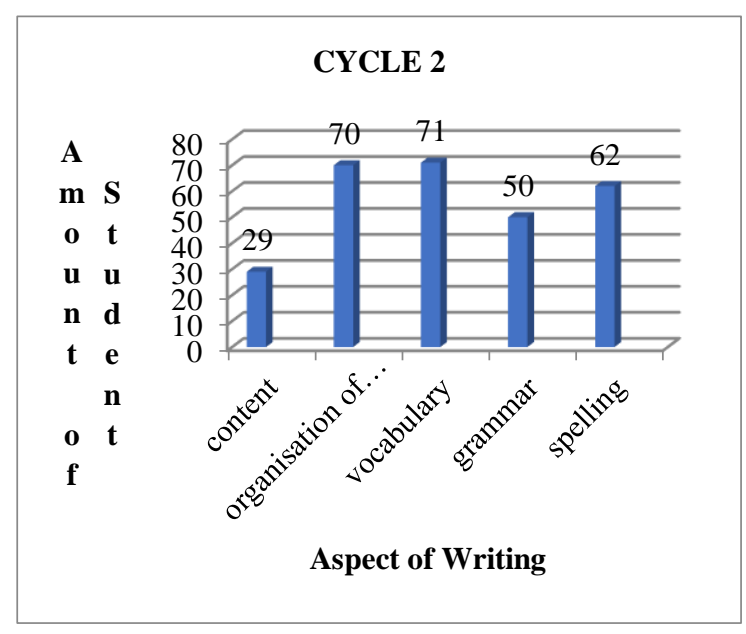

Fig. 5. Results of Narrative Writing Ability in Each Aspect of Cycle 2. 
Based on the figure 5 above, we can know the development of each aspect of writing narrative essay. Good initial skills are in organizational aspects of content, vocabulary and spelling. The three aspects of development have been improved in the cycle 2 of vocabulary aspect to $99 \%$ (71 students), organizational aspect of $97 \%$ (70 students), and aspects of spelling $86 \%$ (62 students).

Inadequate initial capability in content and grammar aspects. But in its development has increased in the second cycle of content aspects reached 40\% (29 students), and grammatical aspects $69 \%$ (50 students). The contents of ideas revealed by students are less creative, this is due to the ability of students to read less than the maximum. The development of sentences in the narrative is also not maximal. This is understandable because lack of adequate portion. This can be known during the research, students have difficulty in developing sentences.

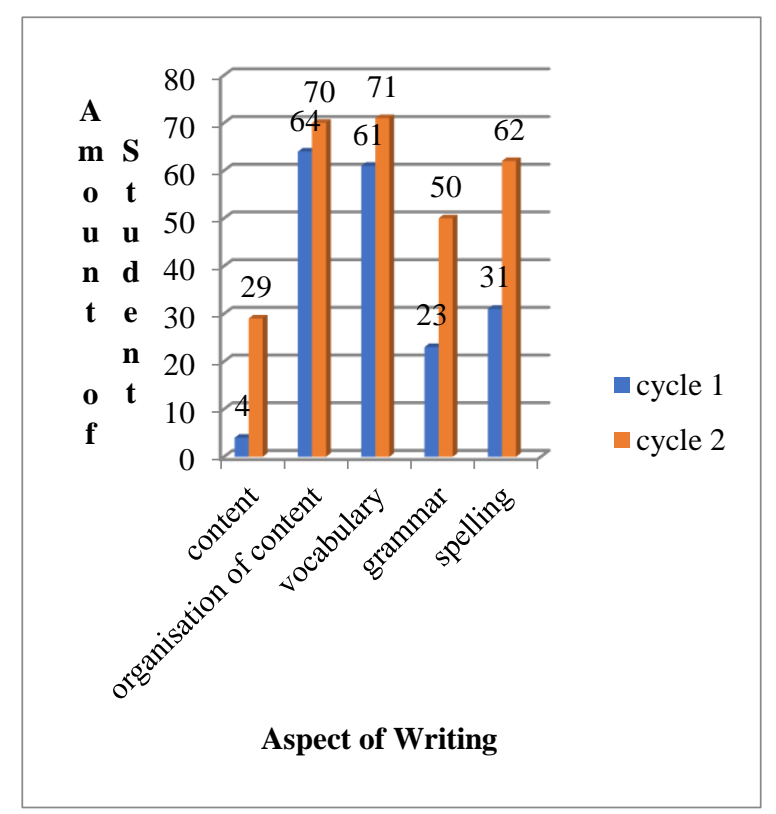

Fig. 6. Results of Narrative Writing from The Perspective of Balance of Brain Function.

This research has a novelty about a model of narrative-based writing balancing brain function in primary school. This learning model is a model that is easy and practical in its implementation. Concrete activity procedures appear in verbal activities balanced by visual and spatial activities. Discussions are not only logical but also intuitive and imaginative. Learning can use effective media or aids. In the implementation of learning, activities can be varied by combining media images, music, concrete objects, and sensory stimuli that can stimulate students to imagine. Learning activities are based on right brain activation activities and left brain in a balanced manner.

This learning model based on balancing brain function makes it easier for students to find ideas that are tailored to different types of intelligence. This is supported by a variety of media that is image, film, recording drama, illustration, concrete objects that can ignite the imagination of students. 
The outcome of this study are expected to develop the theory of learning writing skills in the form of more specific studies of learning-based learning model of balancing brain function in elementary school. Practically the outcome of this study are expected to be useful for teachers. The results of this study can be used for grip and reference learning model that can be utilized in learning Indonesian especially writing narration to get optimal results. Educational policy makers can utilize the results of this study as an additional discourse in determining policies related to the variation and innovation of learning models of writing. The compilers of textbooks can make the results of this study as a reference or a foothold in the preparation of books. Curriculum developers can use the results of this research to develop, manage, and choose curriculum forms that prioritize meaningful, contextual, and respectful learning of individual differences.

\section{Conclusion}

The model of learning to write narrative in primary school from the perspective of balancing brain function through various variations of sensory media can stimulate students to write narrative essays. Learning model of narrative writing in elementary school from the perspective of balancing brain function can be applied as an alternative model of narrative writing lesson. It is proven, through the learning model, the ability of students writing narrative to develop.

\section{References}

[1]B. Percy, The Power of Creative Writing. London: Prentice Hall International, Inc, 1981.

[2]J. W. Pennebaker, Opening up: The healing power of expressing emotions. Guilford Press, 2012.

[3]G. E. Tompkins, Teaching writing: Balancing process and product. Macmillan College, 1994.

[4]D. Nunan, Second Language Teaching \& Learning. ERIC, 1999.

[5]B. DePorter and M. Hernacki, Quantum learning. PT Mizan Publika, 1992.

[6]M. Shahib, Pendidikan Berbasis Kompetensi Menuju Invensi. Bandung: Gema Media Pusakatama, 2005.

[7]A. Hanson, Brain-Friendly Strategies for Developing Student Writing Skills, 2nd ed. California: Corwin Press A SAGE Company, 2009.

[8]D. A. Sousa, How the brain learns. Corwin Press, 2016

[9]H. J. Stolle, "A cognition-based approach toward a general theory of map signs," meta-cartosemiotics, vol. 8, no. 1, pp. 35-41, 2017.

[10]Y. S. Fan, Thinking Maps in Writing Project in English for Taiwanese Elementary School Students, vol. 4, no. 1. 2016.

[11]X. Fazio and T. Gallagher, "Supporting Students 'Writing in Elementary Science: Tools to Facilitate Revision of Inquiry-Based Compositions of Inquiry-Based Compositions," Electr. J. Lit. Through Sci., vol. 8, 2009.

[12]C. E. Smitherman and A. K. Girard, "Creating Connection: Composition Theory and Creative Writing Craft in the First-Year Writing Classroom," vol. 3, no. 2, pp. 49-57, 2011.

[13]C. Shah, K. Erhard, H. Ortheil, E. Kaza, C. Kessler, and M. Lotze, "Neural correlates of creative writing: an fMRI study,” Hum. Brain Mapp., vol. 34, no. 5, pp. 1088-1101, 2013.

[14]M. A. Gülpinar, "The Principles of Brain-Based Learning and Constructivist Models in Education.," Educ. Sci. Theory Pract., vol. 5, no. 2, 2005.

[15]B. Duman, "The Effects of Brain-Based Learning on the Academic Achievement of Students with Different Learning Styles," Educ. Sci. Theory Pract., vol. 10, no. 4, pp. 2077-2103, 2010.

[16]S. J. Martin, "Skills Acquired Through Personal Narrative Writing Instruction," 2010.

[17]B. Joyce, Models of Teaching. New Delhi: Prentice Hall of India, 2003. 
